\title{
Medical Education during COVID-19 Crisis: Challenges and Opportunities
}

\author{
Marhatta MN
}

The new Coronavirus disease (COVID-19) was first identified in December 2019 in Wuhan, China. World Health Organization declared it as pandemic on March 11, 2020. It has spread all most everywhere in the world and has taken 1075750 lives till now. As of September 11, 2020 more than 107755 infected cases and 636 deaths have been reported in Nepal itself.

COVID-19 has severe impact to all spheres of life of the people worldwide. It has deep rooted negative effects not only to the health and well -being of the people but to the socioeconomic aspects of the nations. People have lost their job, productivity and income leading to economic crisis. Fear, anxiety depression insecurity, violation and psychosocial problems are increasing in the societies.

Education system of the country seems all most paralyzed. Medical education and health delivery system have been suffered a lot since the nationwide lockdown announcement by the Government to prevent spread of infection on 24th March 2020. The novel coronavirus disease-2019 pandemic has challenged the structure and delivery of undergraduate and graduate medical education. ${ }^{1}$ Teaching learning activities and clinical postings are either shot down or drastically minimized. Educational institutions have been shut down all over the world for the safety of both students and communities. Social distancing measures hamper students from assembling in learning labs, lecture halls, or small-group rooms and interacting in person. ${ }^{2}$

Inadequate protective facilities, direct prolong exposure to COVID-19 positive cases and asymptomatic cases in the closed working environment and limited health human resources are the major factors contributing to high infection rate in the Health institutions. The Government has instructed to designate $20 \%$ beds in private and $33 \%$ beds in Medical Colleges Teaching Hospitals for COVID-19 patient management. The same faculties, residents and other health professionals are bound to provide health care services to both COVID and nonCOVOID patients in the same health care settings, facilities and hospitals. There is shortage of health professionals due to additional COVID-19 burden on top of regular clinical work with continuous academic activities and by their own sickness, COVID-19 positive status, quarantine and isolation. Recently after release of nationwide lockdown COVID-19 infection rate is getting higher. The infection rate is much higher among the health professionals working in the hospitals and medical colleges. Huge number of faculty teachers, residents, Interns, nurses and other coworkers already are infected. Some health institutes have reported to have as high as $25 \%$ health care workers (HCW) infected. While health workers represent less than $3 \%$ of the population in the large majority of countries and less than $2 \%$ in almost all low- and middle-income countries, around $14 \%$ of COVID-19 cases reported to WHO are among health workers. ${ }^{3}$

COVID-19 crisis has been unique experience for both the faculties and trainees. This has been an opportunity to learn epidemiological aspects, preventive measures, self-protection techniques and the importance of health education to the communities against deadly infectious diseases. It also has taught how to continue Health Professionals academic training and provide health care services during adverse situation and crisis. Many modifications and accommodations has been adopted in the academic programs, teaching learning techniques and time period. The challenge is to maintain quality and standard of medical education so that the future health professionals can have acquisition of adequate knowledge, skills, positive attitudes professionalism and competencies.

Kathmandu University has encouraged to its affiliated colleges to implement Internet based academic activities especially during COVID-19 lockdown period when there was shot down of clinical and class based teaching. After a month of lockdown the theoretical aspects of academic activities was gradually resumed with the new modalities of distance teaching using online technology for the undergraduate training. It has kept the student attached with their course and engaged with educational activities. PG residents and interns were continued with their clinical posting however the teaching were compromised a lot in the new chaotic and uncertain environment since many of the faculties and residents were posted as front-liner on COVID-19 management.

Challenges to medical education during the coronavirus disease-2019 era include engagement over video conferencing and social media platforms, balancing of home and work life, and heightened concerns for provider burnout. ${ }^{1}$ Technology based medical education already has been a main stay for teaching learning activities during the current COVID-19 crisis. Recently online approaches were applied successfully to conduct both the internal assessment and the final practical examination in the KU affiliated Colleges including Nepalgunj Medical College.

Online learning platforms now offer many opportunities that are being widely used by medical collages around the world, comprising of adoptive tutorials, online videos, webcasts, video-conferencing, and virtual models. The range extends from websites, discussions forums, and online discussion 
spaces to real time online chat and a variety of communication apps. ${ }^{4}$ Classroom lectures and tutorials are replaced by online lectures and interactive webinars subsequently.

There has been transformation of medical education and health service system in the form of online teaching and telemedicine in some extend. But these measures have their own limitation that they cannot meet the whole educational objectives of the medical teaching as per university curriculum. Some faculties and students are unable to participate in the teaching learning activities either due to unavailability of good access or inadequately motivated towards the technology driven education system. Most of the classes are one way lectures or slide presentations without interaction and feeling of live presence. The participation of students was encouraging in the initial days and is gradually declining since they lost the interest to the monotonous blind one way teaching. This problem can be solved by making classes more interactive and attractive by using appropriate version of Internet facilities depending upon the objective of subject matter and discipline. It is mandatory to upgrade internet facilities and to have updated soft were programs.

Online teaching lacks hands on training, interaction with the patient, their examination, communication and counseling and the team spirit which are so important to develop clinical skills and professional competencies. The important of human touch in clinical teaching learning cannot fade away but the opportunities for the students will be far less than the preCOVID-19 era. Online teaching is an accepted alternative and the process of paradigm shift has already started globally. ${ }^{5}$ The replacement of in-person classes with online equivalents is an obvious necessity at this time but creates a loss of collaborative experiences that has the potential to be a significant detriment to education. Likewise, the cancellation of clerkships, which are necessary for both skill acquisition as well as for relationship building, is a serious issue which students and medical schools must now resolve. ${ }^{6}$

Medical education seems to be more dependent on the internet technologies in the post COVID-19 era and further. The Government must extend the internet access to the remote and rural communities either. Similarly the medical colleges must give due attention to develop internet infrastructure, capacity building and teachers training for ongoing and future wave-based education.

\section{REFERENCES}

1. Hilburg R, Patel N, Ambruso S, Biewald M A, Farouk S S. Medical Education During the Coronavirus Disease-2019 Pandemic: Learning From a Distance. Adv chronic kidney Dis.2020 (Forthcoming issue). http://doi.org/10.1053/j.ackd2020.05.017.

2. Piryani R, Piryani S, Piryani S, Shankar P, Shakya D. Impact of COVID-19 Pandemic on Medical Education: Challenges and Opportunities for Medical educators in South Asia. Journal of
BP Koirala Institute of Health Sciences.2020; 3(1):28-38. https:// doi.org/10.3126/jbpkihs.v3i1.30318.

3. Keep health workers safe to keep patients safe: WHO 17 September 2020. News release, Geneva.

4. Salyad S, Singh T, Virk A, Mahajan R. Online teaching in medical training: Establishing good online teaching practices from cumulative experience. Int.J.App Basic Med. Research 2020; 10(3):149-155.

5. Acharya R P. 'New Normal' in Medical Education. Journal of Medical Education. 2020; 1(1):13-16.

6. Ferrel M N, Ryan J J. The Impact of COVID-19 on Medical Education. Cureus. 2020; 12(3):e7492. Doi:10.7759/ cureus.7492. 